\title{
Micro-mechanism of Shear Strength and Water Stability Enhancement of Montmorillonite by Microwave Heating
}

\author{
Leping He ${ }^{a}$, Jia Qiu ${ }^{a}$, Qijun Hu ${ }^{a *}$ (1), Haoyu Wang ${ }^{b}$, Shiqing Feng ${ }^{c}$, Yucheng Gu ${ }^{d}$, Junsen Zeng ${ }^{e}$ \\ ${ }^{a}$ Southwest Petroleum University, School of Civil Engineering and Geomatic, Chengdu, 610500, China. \\ ${ }^{b}$ Chongqing University, School of Physics, Chongqing, 400030, China. \\ ${ }^{c}$ China Southwest Geotechnical Investigation \& Design Institute Co., Ltd, Chengdu, 610052, China. \\ ${ }^{d}$ Southwest Petroleum University, School of Geoscience and Technology, Chengdu, 610500, China. \\ ${ }^{e}$ Southwest Petroleum University, School of Mechatronic Engineering, Chengdu, 610500, China.
}

Received: May 31, 2021; Revised: January 09, 2022; Accepted: January 24, 2022

\begin{abstract}
Microwave heating potentially reinforces the muddy intercalation to eliminate slope failure. Montmorillonite has the worst water resistance among the muddy intercalation components, which is a primary facet of inducing muddy intercalation failure. This study investigates the mechanism of shear strength and water stability enhancement of montmorillonite heated by the microwave oven and muffle furnace from room temperature to $800^{\circ} \mathrm{C}$. Results show that montmorillonite mineralogical evolution can be divided into three stages: room temperature- $300{ }^{\circ} \mathrm{C}, 300-600{ }^{\circ} \mathrm{C}$, and $600-800{ }^{\circ} \mathrm{C}$. Microwave heating is more efficient in montmorillonite heat treatment than muffle furnace heating and makes the montmorillonite dehydroxylated earlier. It is worth noting that hot spots formed inside the montmorillonite specimens during the microwave heat treatment. Microwave significantly promotes the shear resistance of montmorillonite, where the maximum increases are $39.94 \%$ of cohesion at $600{ }^{\circ} \mathrm{C}$ and $20.54 \%$ of internal friction angle at $700{ }^{\circ} \mathrm{C}$. This enhancement is due to the rough surfaces and large particles produced by dehydroxylation and $\mathrm{Mg}$-Al spinel synthesis, and the significant degree of disorder state of MMT after dehydroxylation also plays a vital role. The microwave-heated montmorillonite over $500{ }^{\circ} \mathrm{C}$ presents good integrity in the water immersion test over $24 \mathrm{~h}$. Considering the shear behavior and water stability, we believe the most reasonable heating interval for microwaves is $500-600^{\circ} \mathrm{C}$.
\end{abstract}

Keywords: Montmorillonite, Microwave heating, Muffle furnace heating, Shear behavior, Water stability, Microstructure.

\section{Introduction}

The muddy intercalation is a weak material between the upper and lower rock layers in the argillaceous slope, consisting of quartz, clay minerals, calcite, and feldspar ${ }^{1-3}$. And the slopes containing muddy intercalations are prone to slide driven by heavy rainfall or earthquake, resulting in catastrophic economic losses and casualties ${ }^{4}$. The shear failure of muddy intercalation under the water function is mainly due to the clay minerals swelling and softening ${ }^{5-7}$. The clay minerals take account for $60 \%$ of muddy intercalation ${ }^{2,3,8}$, and among which the montmorillonite (MMT) presents the worst water resistance ${ }^{9,10}$. Therefore, ameliorating MMT properties probably reinforces muddy intercalation to prevent structural failure from heavy rainfall or high groundwater content.

The MMT crystal has a unique 2:1 layered structure that two inward-pointing tetrahedral sheets sandwich one octahedral sheet ${ }^{11}$. This structure easily absorbs the environmental water and then swells ${ }^{12,13}$. Besides, the MMT crystal presents the highest cation exchange capacity compared to other clay minerals ${ }^{10,14}$. High-temperature treatment is a popular approach

*e-mail: huqijunswpu@163.com to modify MMT by increasing adsorption ${ }^{15}$. The pure MMT undertakes dehydration, dehydroxylation, layered structure collapsing, and decomposition/melting-recrystallization with a temperature ranging from room temperature to $1000^{\circ} \mathrm{C}^{14,16-18}$. Besides, the thermal stability, the structural transformation process, and the high-temperature products of MMT were significantly influenced by the interlayer species ${ }^{19}$. Furthermore, some investigations involve the MMT structural evolution in bentonite via high-temperature treatment ${ }^{17,20}$. These bentonites generally contain inclusions, e.g., clay minerals (kaolinite, illite, and chlorite) and nonclay minerals (silica polymorphs, zeolites, feldspar, and carbonates) ${ }^{17}$. However, these inclusions fail to affect the start-stop temperature of the crystal structure changes of MMT.

Microwave-assisted heating is an efficient thermal treatment that fastens the reaction time ${ }^{21,22}$; e.g., microwave-assisted acid treatment modifies MMT $^{23-25}$. However, the treatment temperatures in these investigations are lower than $100^{\circ} \mathrm{C}$. Regarding the microwave-assisted high-temperature treatment, Santana et al. considered the structural evolution of clay at microwave and conventional heat functions; still, they lacked investigating the pure MMT under microwave-assisted heat treatment ${ }^{26}$. In our previous study, microwave heating has 
been proven to enforce muddy intercalation effectively ${ }^{27}$. However, the role of MMT played in the reinforcement was not identified. Although MMT probably presents a similar process exposed to microwaves and conventional resistance heating, its shear behavior and water stability after microwave treatment have not been investigated, which is vital to further the microwave reinforcement mechanism for muddy intercalation.

This study conducted microwave heating and muffle furnace heating of MMT specimens and compared the test results. The crystal phases were characterized by X-ray powder diffraction. The micromorphology was observed by scanning electronic microscopy. The shear behavior was measured by the direct shear test. The water immersion test estimated the water stability.

\section{Materials and Methodology}

\subsection{Material properties and specimen preparation}

The MMT sample was provided by Chengyu Mineral Products CO. Ltd and ground to 200 mesh. In order to obtain the oxide composition and mineral composition of the MMT samples, a small amount of received MMT powder samples were dried at $105^{\circ} \mathrm{C}$ for 4 hours. Then the XRF and XRD tests were performed, respectively. Furthermore, the XRF result is shown in Table 1. A $150 \mathrm{~g}$ powder sample was mixed with deionized water at a mass ratio of 1:0.2. The well-mixed sample was compacted to a cylindrical-shaped specimen with a diameter of $50 \mathrm{~mm}$ and a height of $50 \mathrm{~mm}$. Subsequently, the cylindrical specimens were dried at $105^{\circ} \mathrm{C}$ for four hours to remove the moisture. Eventually, the specimen was wrapped in plastic film to prevent environmental contamination.

\subsection{Heating apparatus and experimental conditions}

The used microwave apparatus was custom-made by CHANGEMW Co. Ltd, as shown in Figure 1. The apparatus comprises a single microwave source, water coolant, metal cavity (length, width, and height are $25 \mathrm{~cm}, 30 \mathrm{~cm}$, and $26 \mathrm{~cm}$, respectively), BJ-26 waveguide, operating system, and power supply, touch panel, infrared thermometer, and alumina fiber. The microwave with $2.45 \mathrm{GHz}$ in frequency is generated by the microwave source and propagates from the source to the cavity through the waveguide. The microwave heating experiment used the temperature control mode, where the output power is adjusted from $0.5 \mathrm{~kW}$ to $1.4 \mathrm{~kW}$ based on the preset temperature curve. Before microwave heating, the MMT specimens were held up with an alumina ceramic plate, avoiding direct contact between the specimen and the insulation material in the cavity, which might cause the high-temperature specimen to stick to the insulation material. And then each specimen was individually heated.

The muffle furnace used is an $\mathrm{SX}_{2}-5-12 \mathrm{~A}$ box resistance furnace. The output power is $5 \mathrm{~kW}$, the length, width, and height of the cavity are $300 \mathrm{~mm}, 200 \mathrm{~mm}, 120 \mathrm{~mm}$, individually. 2-3 specimens were put into the cavity for heat treatment in each batch.

All specimens were heated to preset maximum temperature (300-800 ${ }^{\circ} \mathrm{C}$ at $100{ }^{\circ} \mathrm{C}$ increments) and held for $30 \mathrm{~min}$, and

Table 1. XRF results of MMT sample.

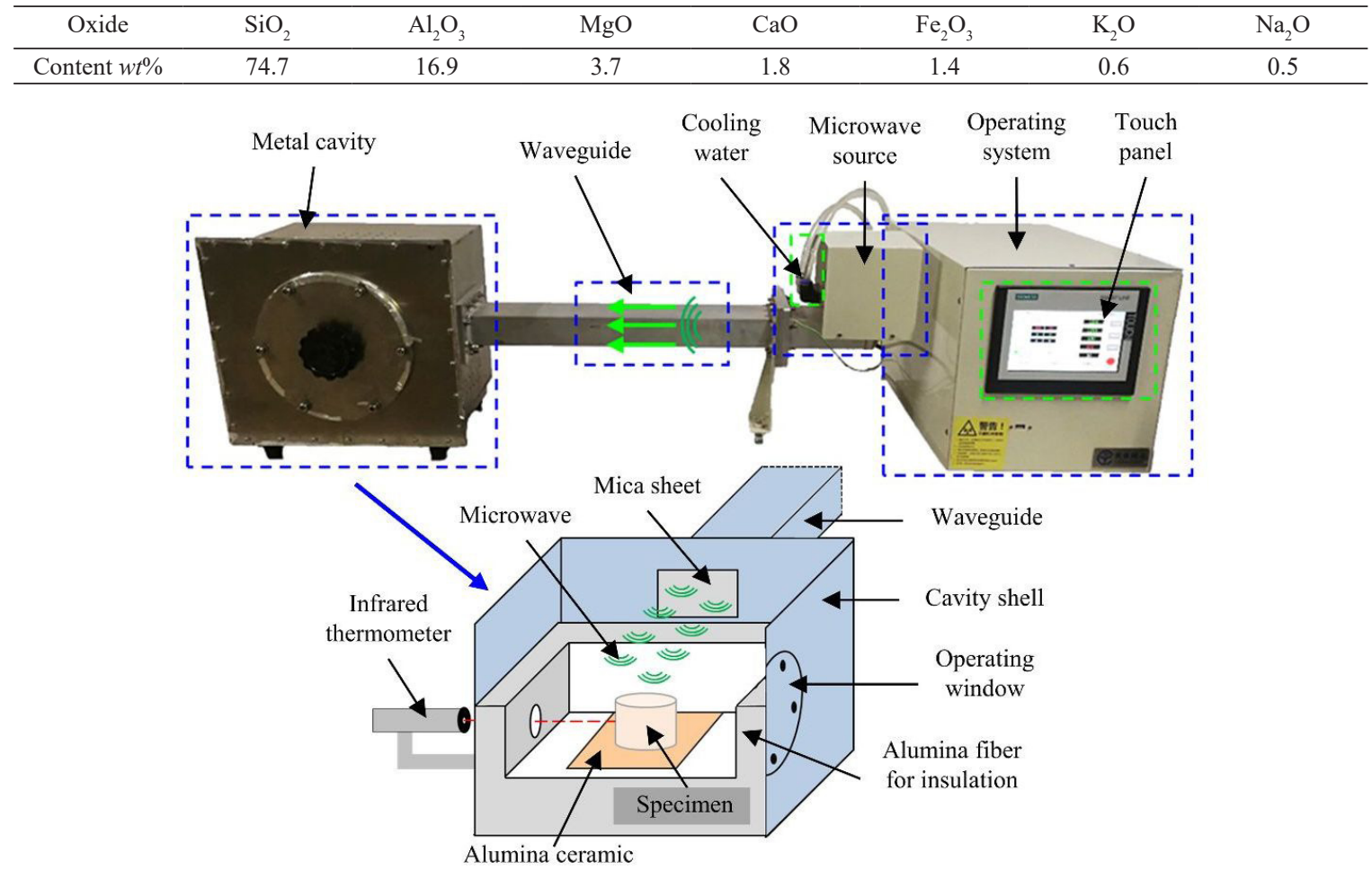

Figure 1. Schematic diagram of microwave heating apparatus. 
after that, the power was shut down, and the specimens were allowed to cool to room temperature in the cavity. It is worth noting that five specimens were included for comparison at each temperature, and a total of 60 high-temperature treated MMT specimens were produced; among them, the microwave heated specimens and muffle furnace heated specimens are half each.

\subsection{Characterization methods}

\subsubsection{Thermogravimetric analysis}

The thermogravimetric analysis was performed on the received MMT powder samples. The analyzer used is the Netzsch STA 449C synchronous thermal analyzer, heated in the air atmosphere from room temperature to $900{ }^{\circ} \mathrm{C}$ at a heating rate of $5^{\circ} \mathrm{C} / \mathrm{min}$.

\subsubsection{Mass loss of heat-treated specimens}

Five specimens heated at the same temperature are conducted to determine the average mass loss produced by the two heat treatment methods.

\subsubsection{Direct shear test}

A total of 55 cylindrical specimens with a diameter and height of about $5 \mathrm{~cm}$ were conducted to the direct shear test by a YZW-30 shear instrument, including 5 specimens dried in the oven at $105^{\circ} \mathrm{C}, 25$ microwave heat-treated specimens (300-700 ${ }^{\circ} \mathrm{C}, 5$ specimens at the same temperature), and 25 muffle furnace heat-treated specimens $\left(300-700{ }^{\circ} \mathrm{C}, 5\right.$ specimens at the same temperature). The preset normal stress adopted is $0-2 \mathrm{MPa}$ at $0.5 \mathrm{MPa}$ increments. As shown in Figure 2, after applying the preset normal stress, the shear force was applied continuously until damage to the specimen, and the maximum shear force was recorded. Then, calculate the actual normal stress and shear stress (due to the sample shrinkage, the diameter is not the standard $5 \mathrm{~cm}$, so the actual stress needs to be calculated) of the same set of specimens ( 5 specimens at the same temperature). Then draw the same set of data in the analysis software with normal stress as the $\mathrm{x}$-axis and shear stress as the y-axis. Finally, according to the linear fitting results of 5 points, the y-axis intercept is the cohesion, and the slope of the straight line is the internal friction angle. That is the method to obtain the shear strength parameters of the specimens. Of course, it is worth noting that if data deviate too much in the same set, it can be deleted to obtain the best linear fitting result.

\subsubsection{XRPD test}

The fragments of each specimen after the direct shear test were collected separately. In order to explore whether the

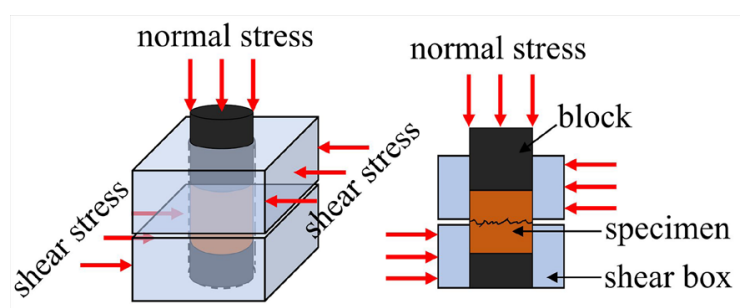

Figure 2. Schematic diagram of direct shear test. microwave heating caused hot spots inside the specimens, the internal and external fragments of specimens (one specimen at the same temperature) were selected separately and ground into 200 mesh with an agate mortar. Then the powder samples were prepared for the XRPD test. For comparison, the specimens heated by the muffle furnace are subjected to the same operation. The mineralogical compositions of the specimens heat-treated by microwave and muffle furnace were determined over the range of $3-65^{\circ}(2 \theta)$ at a scanning rate of $5 \% \mathrm{~min}$ on an Ultima IV multipurpose X-ray powder diffractometer (XRPD). The measurements were conducted at $40 \mathrm{kV}$ and $40 \mathrm{~mA}$ with $\mathrm{Cu}-\mathrm{K} \alpha$ radiation $(\lambda=1.54056 \AA)$. The chemical formula of MMT, the interlayer space of MMT crystals, and the crystalline phase quantification were carried out in Jade 6.5. The mass percentage of MMT is calculated by the $\mathrm{K}$ value method.

\subsubsection{SEM test}

In order to clarify the microstructure of MMT under microwave heating, especially the development of microcracks and micro-pores, we carried out scanning electron microscopy tests on MMT samples before and after microwave treatment. The samples were selected from the surface of the fragments after the direct shear test and polished by sandpaper. We used a ZEISS EVO MA 15 SEM instrument, the secondary electron imaging mode was used in the test, the accelerated voltage, emission current, and working distance are $20 \mathrm{kV}, 50 \mathrm{~mA}$, and $9.5-11.5 \mathrm{~mm}$, respectively.

\subsubsection{Water immersion test}

We conducted the water immersion test for the MMT samples after heat treatment. After the direct shear test, we selected the appropriate size fragments of the MMT specimens and smoothed the surface with sandpaper. Then weigh the mass of each fragment, put the fragments into the $800 \mathrm{~mL}$ beaker individually, and put 20 times the mass of deionized water of the fragments in the beaker, then the immersion test began. It is worth noting that the $\mathrm{pH}$ of the deionized water we used is 6.32 . After $24 \mathrm{~h}$ of immersion, we observed the fragments in the beaker and estimated the water stability based on the integrity of the MMT fragments. Finally, we explored the effect of long-term immersion in water on the mineralogical composition of MMT specimens. After 20 days of soaking, the specimens were taken out and dried at $105{ }^{\circ} \mathrm{C}$ for 4 hours, then ground to 200 mesh and characterized by XRPD.

\section{Results and Discussion}

\subsection{Thermogravimetric analysis}

The thermogravimetric curve of received MMT samples is shown in Figure 3. Combined with the DTG curve, the thermogravimetric change of MMT can be divided into four stages. The first stage is from room temperature to $196^{\circ} \mathrm{C}$. At this stage, the mass loss reaches $11.3 \%$, and MMT loses adsorbed water and interlayer water on a large scale. Stage II is from $196{ }^{\circ} \mathrm{C}$ to $508.3^{\circ} \mathrm{C}$, with a low mass loss, mainly continuing to lose the small amount of incompletely removed interlayer water. But when the temperature exceeds $508.3^{\circ} \mathrm{C}$, before $719.2^{\circ} \mathrm{C}$, the mass loss of MMT speeds up 
again. The mass loss at this stage reaches $4.25 \%$, which is mainly caused by the dehydroxylation of MMT. When the temperature exceeds $719.2^{\circ} \mathrm{C}$, the mass of MMT decreases at a low rate, caused by the evaporation of hydroxyl groups that were incompletely removed in the previous stage.

\subsection{Mineralogical and microstructure evolution}

Figure 4 a illustrates the XRPD patterns of MMT before and after microwave heating. Owing to the un-uniform heating of the microwave, the powders samples used for XRPD tests were sampled from the surface of the MMT specimens to prevent the test results from interfering caused by hot spots. The XRPD results showed that the MMT belongs to the calcium-based MMT (Ca0.2( $\left.\mathrm{Al}, \mathrm{Mg})_{2} \mathrm{Si}_{4} \mathrm{O}_{10}(\mathrm{OH})_{2} \cdot 4 \mathrm{H}_{2} \mathrm{O}\right)$, which mainly consists of $57 \%$ MMT, $30.7 \%$ cristobalite, $5.3 \%$ albite, and $4 \%$ quartz. The interlayer space is calculated as $15.0937 \AA$ in the received MMT samples, and it reduces to $9.7212 \AA$ at $300{ }^{\circ} \mathrm{C}$. Besides, the value of $2 \theta$ of MMT diffraction peak offsets from $5.6^{\circ}$ of $105{ }^{\circ} \mathrm{C}$ to $9.1^{\circ}$ of $300^{\circ} \mathrm{C}$, which also proves the interlayer spacing reduction. Subsequently, the intensity of the MMT diffraction peak keeps constant at $300-600^{\circ} \mathrm{C}$. However, it sharply decreases at $600-700{ }^{\circ} \mathrm{C}$, and a small amount of magnesia-alumina

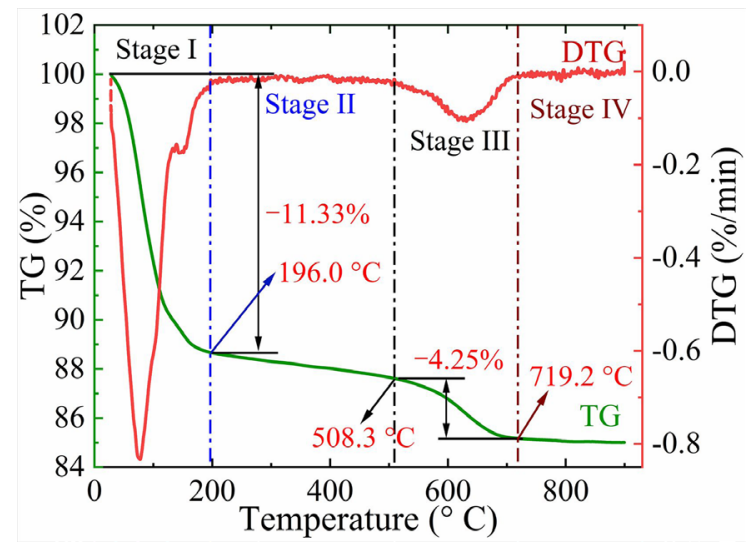

Figure 3. Thermogravimetric curve of received MMT samples. spinel peaks are detected at $700{ }^{\circ} \mathrm{C}$. Eventually, when the temperature reaches $800{ }^{\circ} \mathrm{C}$, the MMT diffraction peak intensity was further reduced, and an apparent increase is observed in magnesia-alumina spinel and cristobalite. The mass percentage of these minerals can be seen in Figure $3 \mathrm{~b}$.

The mineralogical changes of microwave heat-treated specimens reveal three stages in the MMT microstructure evolution, which are $105-300{ }^{\circ} \mathrm{C}, 300-600{ }^{\circ} \mathrm{C}$, and 600 $800{ }^{\circ} \mathrm{C}$, respectively. The MMT crystal advantages in the absorption and cation exchange capacity, numerous adsorbed water exists among the MMT particles, and numerous interlayer water exists in the interlayer space ${ }^{28}$. The MMT exposed to microwaves dehydrates the adsorbed water and interlayer water at $105-300{ }^{\circ} \mathrm{C}^{17}$. Since the adsorbed water and interlayer water are non-combined water, the MMT crystal avoids structural failure, but the interlayer space reduces among particles and crystal layers ${ }^{29}$. Consequently, MMT can still be detected from the XRPD patterns, exhibiting the diffraction peaks to offset and the interlayer space to reduce. The MMT continues to dehydrate at $300-600{ }^{\circ} \mathrm{C}$ and initiates to dehydroxylate at an uncertain temperature between 300-600 ${ }^{\circ} \mathrm{C}$, and this is evidenced by the MMT's diffraction peaks offset and intensity reduction in XRPD patterns. The $\mathrm{OH}^{-}$loss in Al-O octahedron destroys the crystal structure to induce the diffraction peaks intensity to decrease ${ }^{16}$, as shown in Figure 4. During this stage, the dehydroxylated MMT gradually decomposes and recrystallizes to form the $\mathrm{Mg}-\mathrm{Al}$ spinel. However, Wu et al. and Chen et al. declared that the MMT formed cordierite at $900{ }^{\circ} \mathrm{C}^{16,19}$. This difference is due to the relatively high alumina content $(16.941 \%)$ in the received samples. Schreyer et al. explained that alumina's high content in the $\mathrm{MgO}-\mathrm{Al}_{2} \mathrm{O}_{3}-\mathrm{SiO}_{2}$ system would lead to spinel formation $^{30}$. Besides, Wu et al. indicated that the presence of cristobalite could increase the required temperature to form cordierite due to the low activation of cristobalite at high temperatures ${ }^{31}$. Therefore, the high content cristobalite suppresses the cordierite to form and promote the synthesis of Mg-Al spinel.

Figure 5 illustrates the comparison between the inside and outside of the microwave heat-treated specimens (marked
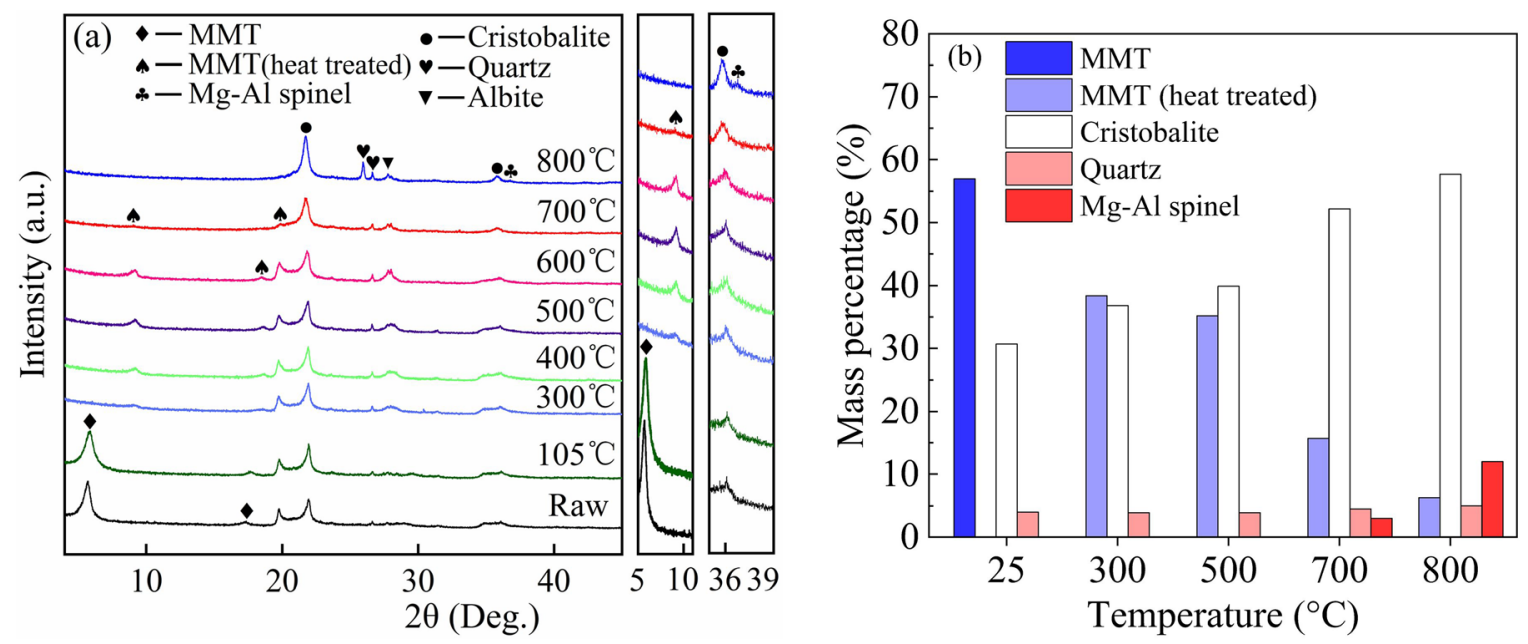

Figure 4. XRPD patterns and quantitative of MMT before and after microwave heating. 


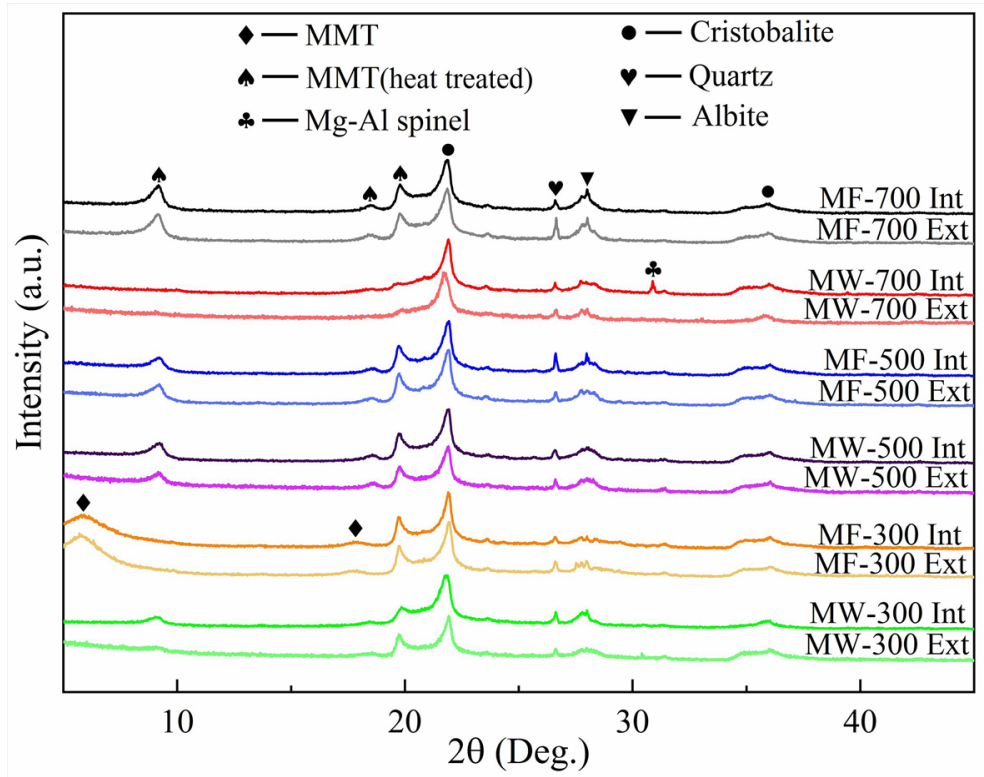

Figure 5. Internal and external comparison of the heat-treated specimens.

with MW) and muffle furnace heat-treated specimens (marked with MF) at $300{ }^{\circ} \mathrm{C}, 500{ }^{\circ} \mathrm{C}, 700{ }^{\circ} \mathrm{C}$. First, the XRPD patterns of specimens produced by different heat treatment methods are significantly different at 300 and $700{ }^{\circ} \mathrm{C}$. At $300{ }^{\circ} \mathrm{C}$, the specimens heat-treated in the muffle furnace have almost no diffraction peaks shift than the samples dried at $105^{\circ} \mathrm{C}$. This phenomenon means that the interlayer water of muffle furnace heat-treated specimens did not remove on a large scale. And the microwave heat treatment seems to make the MMT diffraction peak disappear faster, whether internal (marked with INT) or external (marked with EXT). The XRPD patterns at $500{ }^{\circ} \mathrm{C}$ are relatively similar. In addition, we first pay attention to the microwave heat-treated specimens for the inside and outside of the same specimen. We can find that the XRPD patterns of the internal and external specimens heat-treated by microwave at $300,500{ }^{\circ} \mathrm{C}$ are the same, but at $700{ }^{\circ} \mathrm{C}$, the $\mathrm{Mg}$-Al spinel diffraction peaks are more prominent inside the specimen. And more $\mathrm{Mg}$-Al spinel diffraction peaks were also detected in the microwave heat-treated MMT specimen at $800^{\circ} \mathrm{C}$, as shown in Figure 3. As we know, microwave heating poses a characteristic of provisioning high microwave energy into dielectric materials with deeper penetration for internal heat generation $^{21}$. The phenomenon we observed confirms that during the microwave heat treatment of the MMT specimen, hot spots with a higher temperature than the actual external monitoring temperature were formed inside the specimen. In addition, for comparing the internal and external heat-treated specimens in the muffle furnace, the internal and external XRPD results after heat treatment at the same temperature are the same, which means that we can regrade the muffle furnace heat treatment as uniform heating.

From the XRPD results, we found two critical phenomena. The first phenomenon is that the microwave heat treatment of MMT specimens has higher efficiency, and at the same heat treatment temperature, the microwave heating reaction process is faster. The second important phenomenon is the existence of hot spots inside the microwave heat-treated MMT specimens. In fact, for the first phenomenon, the research of Whittaker ${ }^{32}$ shows that the electric field component of the microwave radiation could concentrate the lattice defects and enhance ion mobility at the interface. The presence of microwaves will improve the rate of mass transport at a given temperature. Therefore, the first phenomenon is supported by literature, and microwave heating has an efficiency advantage compared with muffle furnace heating. In addition, regarding the hot spots that may exist in the microwave heat-treated specimens, because of the complicated phase composition of the MMT samples, the dielectric constant of the samples is difficult to calculate, so it is difficult to predict the location of the hot spot inside the specimen, so we sampled from the surface of the specimen and the center of the specimen and conducted the XRPD tests. Fortunately, we confirmed the existence of the hot spot through the XRPD tests.

Compared with muffle furnace heat treatment, microwave heat treatment accelerates the reaction process when heating the MMT specimens. However, from the XRPD results of the specimens heat-treated at 300,500 , and $700^{\circ} \mathrm{C}$, the reaction process of the muffle furnace heat-treated specimens is still consistent with the microwave heat-treated specimens. Still, the muffle furnace must provide a higher temperature to achieve the same process as the microwave heat treatment. Therefore, we carried out the scanning electron microscope observation on the microwave heat-treated specimens to explore the influence of high-temperature heat treatment on the microstructure of MMT.

Figure 6 presents the micromorphology of specimens before and after microwave heating. Generally, the $105^{\circ} \mathrm{C}$ dried specimen has a dense structure without large cracks. It presents some narrow cracks with a diameter of fewer than 1 $\mu \mathrm{m}$ which accompanies few tiny pores. These cracks" width propagates to $2-3 \mu \mathrm{m}$ at $300{ }^{\circ} \mathrm{C}$, so do the pores. Figure $6 \mathrm{c}$ 
still clearly identifies the layer structure of MMT. When the temperature exceeds $600-700{ }^{\circ} \mathrm{C}$, the structure became more porous. Some of the mineral particles that occluded together mechanically are chemically combined under the effect of a high temperature, and some cracks are observed on the aggregate's edge. The temperature of $800{ }^{\circ} \mathrm{C}$ creates some layered particles with sharper edges than those at lower temperatures in the MMT. By comparing the SEM images of $\mathrm{Mg}-\mathrm{Al}$ spinel in the research of $\mathrm{Li}$ et $\mathrm{al}^{33}$, we think this substance is $\mathrm{Mg}-\mathrm{Al}$ spinel.

\subsection{Macro-morphology and physical properties}

Figure 7 shows the specimen macro-morphology before and after heat treatment. The color of specimens changed from the light olive of the virgin specimen to white at $105{ }^{\circ} \mathrm{C}$, then became pale-yellow with the temperature increasing. Besides, numerous cracks occur after microwave
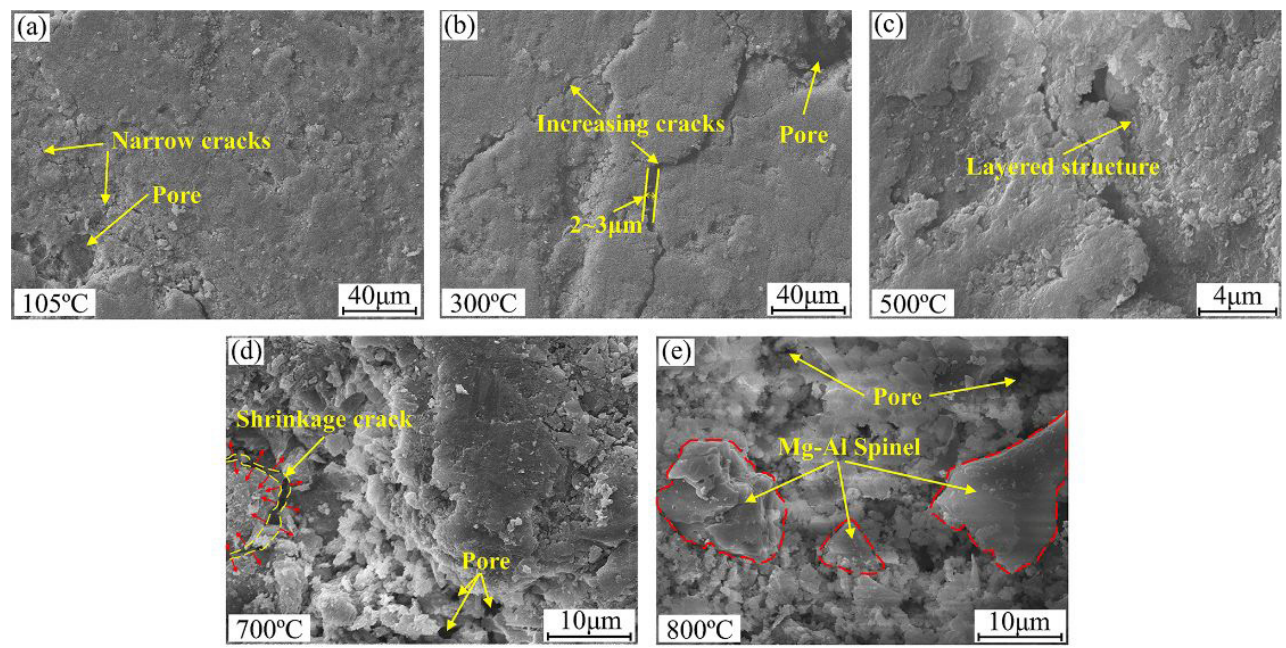

Figure 6. SEM images of MMT specimens before and after microwave heating.
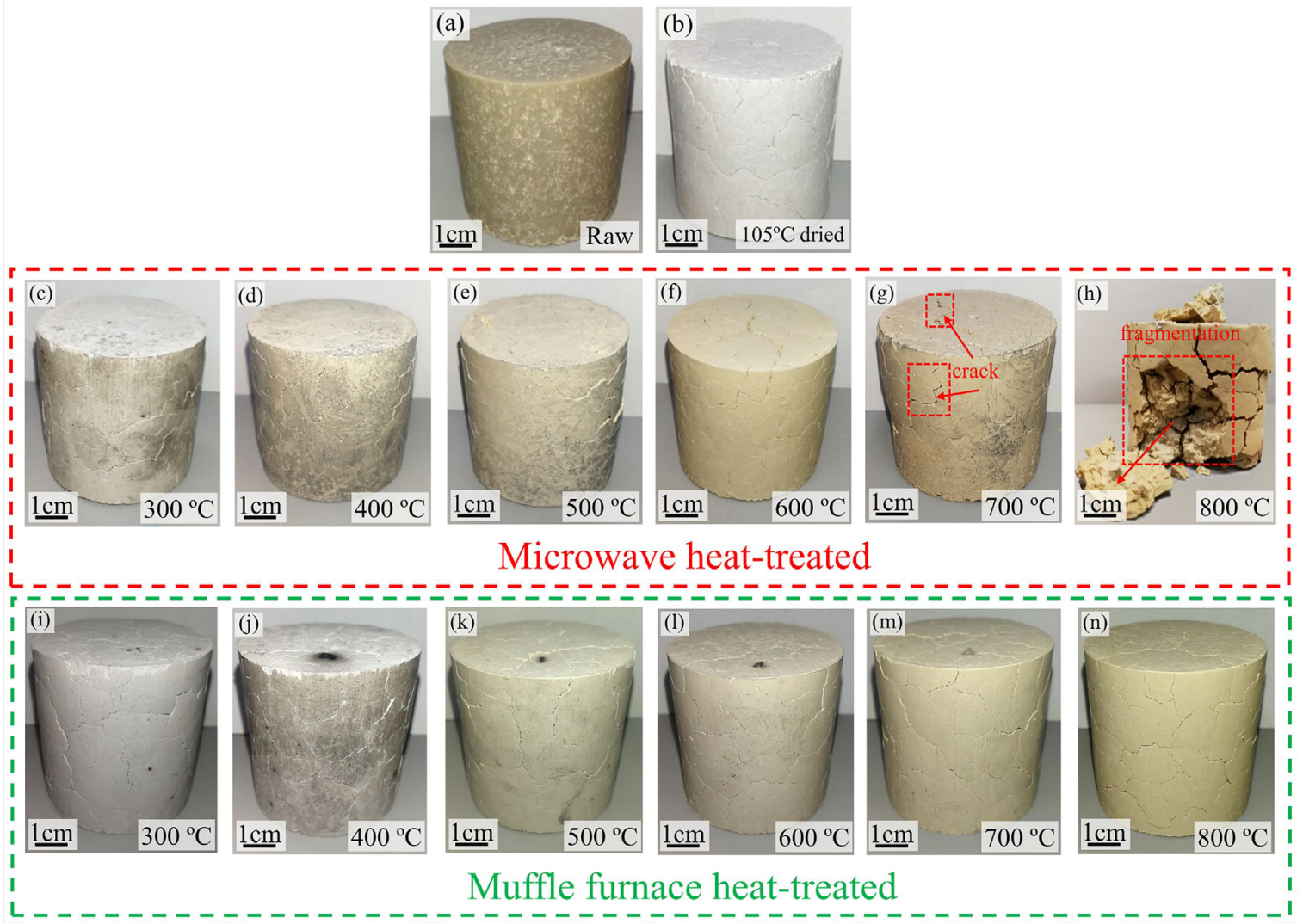

Figure 7. Specimen macro-morphology before and after heat treatment. 
heat treatment, and the number increases as temperature rise. When the temperature reaches $700{ }^{\circ} \mathrm{C}$, the cracks of microwave-heated specimens expand obviously, and the specimens lose their integrity at $800^{\circ} \mathrm{C}$. In comparison, the crack development of the muffle furnace heat-treated specimens is more stable. From $300{ }^{\circ} \mathrm{C}$ to $800^{\circ} \mathrm{C}$, the number of cracks on the specimens' surfaces gradually increases, but the size does not increase significantly, especially for the specimens heated at 700 and $800^{\circ} \mathrm{C}$. The muffle furnace heat-treated specimens still kept good integrity, unlike the specimens after microwave treatment.

In fact, we can clearly see from Figure 7 that at 300$600{ }^{\circ} \mathrm{C}$, the crack development of the specimens produced by the two different heating methods is similar. But when the temperature reaches 700 and $800^{\circ} \mathrm{C}$, the crack development shows a significant difference, reflecting the different effects of microwave and traditional heating on MMT specimens. We guess that the formation of this phenomenon is related to the hot spots inside the microwave-heated MMT specimens, and the existence of hot spots has been confirmed in section 3.2. We believe that the hot spot will lead to the rapid increase of cracks and destroy the integrity of the specimens.

The comparison of specimens' mass loss heated by two methods is shown in Figure 8. The green line in the figure

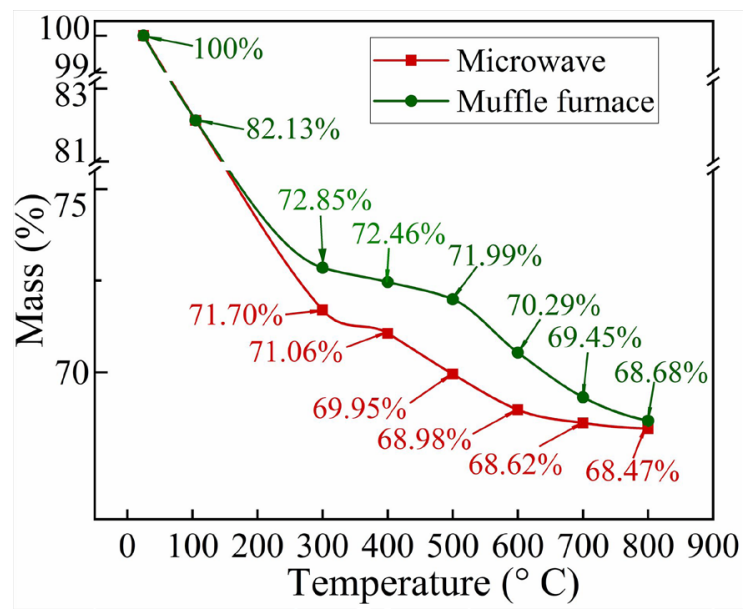

Figure 8. Specimen mass loss before and after heat treatment.

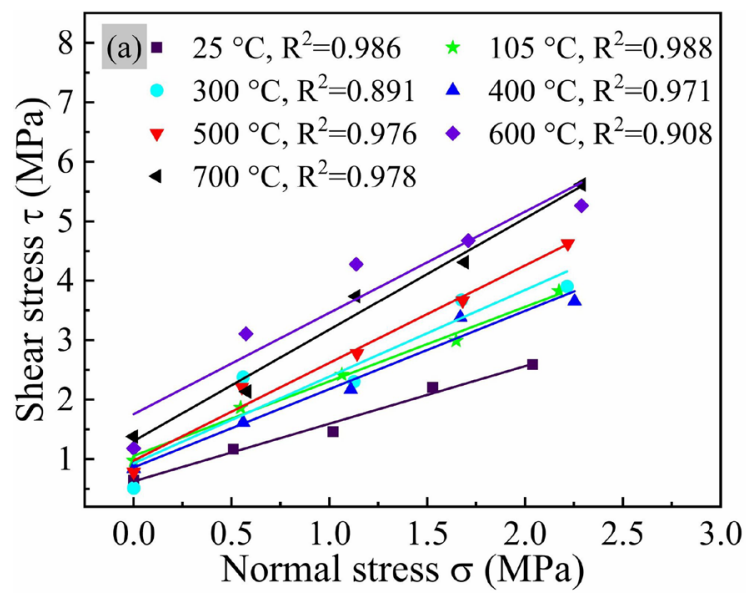

illustrates the mass change curve of the specimens after heat treatment in the muffle furnace. Compared with the thermogravimetric curve of the received sample shown in Figure 2, the trends of the two curves are the same. However, the mass change curve of the specimens after microwave heat treatment shown by the red line is obviously different from the two curves mentioned above. We can learn from the thermogravimetric curve that MMT will remove a large amount of absorbed water and interlayer water at room temperature $-196^{\circ} \mathrm{C}$, and dehydroxylate at $508.3^{\circ} \mathrm{C}-719.2^{\circ} \mathrm{C}$, this process can obviously correspond to the specimens heat-treated in the muffle furnace. However, the mass of the specimens heat-treated in the microwave oven began to drop significantly before 500 . This phenomenon corresponds to the faster microwave heating process observed in Section 3.2. The mass of the microwave heat-treated specimens re-started to drop sharply at about $400{ }^{\circ} \mathrm{C}$, and it started to level off around $700{ }^{\circ} \mathrm{C}$. However, the mass of the muffle furnace heat-treated specimens re-started to drop sharply at about $500{ }^{\circ} \mathrm{C}$, and it continues to decrease at $700-800{ }^{\circ} \mathrm{C}$. This phenomenon proves that the microwave can effectively increase the thermal reaction rate of MMT once again.

\subsection{Shear behavior}

As shown in Figure 9, linear fitting was performed with the maximum shear stress and actual normal stress obtained in the direct shear test. The y-axis intercept and slope of the straight line are the specimens' cohesion and internal friction angle, respectively. Table 2 presents the cohesion and internal friction angle of the specimens heat-treated by microwave and muffle furnace. Figure 10a and Figure 10b illustrate the cohesion and internal friction angle of specimens before and after heat treatment by the microwave oven and muffle furnace. Because the microwave heat-treated specimens lost their integrity at $800^{\circ} \mathrm{C}$, the direct shear test results did not involve the $800{ }^{\circ} \mathrm{C}$ heat-treated specimens. The cohesion and internal friction angle are calculated and fitted by the Akima spline in Origin Pro 2020.

High-temperature heat treatment significantly increases the MMT resistance to shear behavior. The microwave heattreated specimens present the highest cohesion at $600{ }^{\circ} \mathrm{C}$, which is $1.76 \mathrm{MPa}$, and the cohesion of the muffle furnace

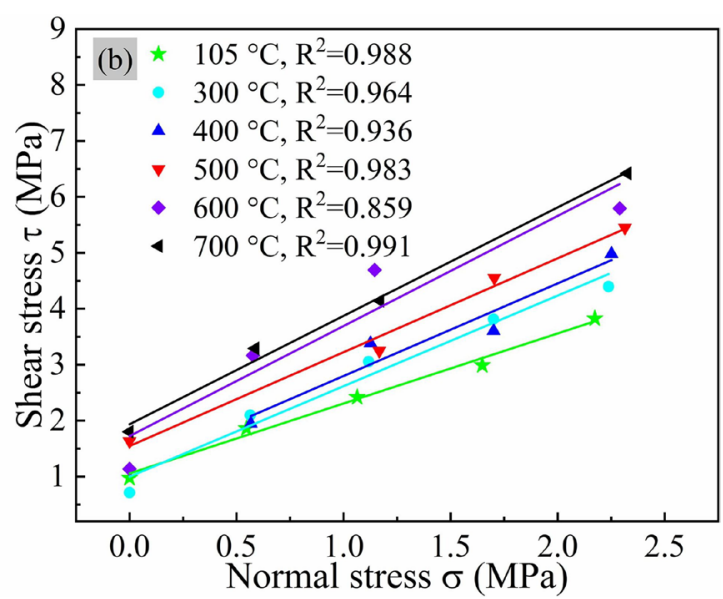

Figure 9. Linear fitting results of MMT specimens after the direct shear test. 
Table 2. Cohesion and internal friction angle of specimens.

\begin{tabular}{|c|c|c|c|c|c|c|c|c|}
\hline \multicolumn{2}{|c|}{ Temperature $\left({ }^{\circ} \mathrm{C}\right)$} & 25 & 105 & 300 & 400 & 500 & 600 & 700 \\
\hline \multirow{2}{*}{ Cohesion (MPa) } & Microwave & 0.63 & 1.05 & 0.93 & 0.86 & 0.98 & 1.76 & 1.30 \\
\hline & Muffle & 0.63 & 1.05 & 0.99 & 1.14 & 1.55 & 1.72 & 1.93 \\
\hline \multirow{2}{*}{ Internal friction angle $\left(^{\circ}\right)$} & Microwave & 44.1 & 51.4 & 55.6 & 52.8 & 58.6 & 59.6 & 61.9 \\
\hline & Muffle & 44.1 & 51.4 & 57.4 & 58.9 & 59.2 & 59.3 & 61.5 \\
\hline
\end{tabular}

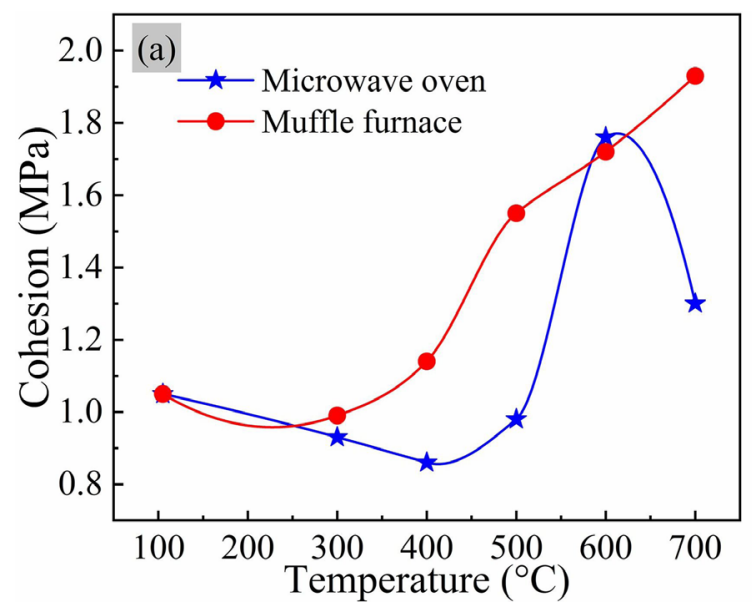

Figure 10. Comparison of shear behavior of MMT specimens.

heat-treated specimens reached $1.93 \mathrm{MPa}$ at $700{ }^{\circ} \mathrm{C}$. However, the cohesion of microwave heat-treated specimens decreased slightly at $105-400{ }^{\circ} \mathrm{C}$, and the cohesion of muffle furnace heat-treated specimens slightly reduced at $105-300{ }^{\circ} \mathrm{C}$. Combining sections 3.2 and 3.3, we know that the MMT specimens continue to dehydrate at $105-400{ }^{\circ} \mathrm{C}$, and the cohesion should theoretically increase as the intermolecular force increases due to the interlayer spacing reduction. However, we cannot ignore the macro-crack propagation inside the specimens also because of the interlayer spacing reduction. The cohesion of the microwave heat-treated specimens continues to decrease to $400{ }^{\circ} \mathrm{C}$ before it increases, but the cohesion of the muffle furnace heat-treated specimens continues to rise from $300^{\circ} \mathrm{C}$ to $700^{\circ} \mathrm{C}$. We observed above is because microwave heat treatment has higher efficiency, which leads to faster dehydration and dehydroxylation of the specimens. Because the water in the microwave heattreated specimens loses more and faster than that of the muffle furnace heat-treated specimens, and hot spots will be generated during the microwave heating process, which causes the better development of cracks inside the specimens. The porous structure lacks strong contact points to resist a higher shear force. Therefore, the cohesion of the muffle furnace heat-treated specimens is greater than that of microwave heat-treated specimens. The cohesion of the microwave heat-treated specimens exceeds that of the muffle furnace heat-treated specimens until the large-scale dehydroxylation of the microwave heat-treated specimens is at $500-600{ }^{\circ} \mathrm{C}$. On the one hand, the structure of the specimens shrank due to dehydroxylation, and some larger size of particles were formed, accompanied by numerous shrinkage cracks, resulting in an increase in the internal roughness of the specimens. And at $700{ }^{\circ} \mathrm{C}$ and above, $\mathrm{Mg}$ - $\mathrm{Al}$ spinel appeared in the

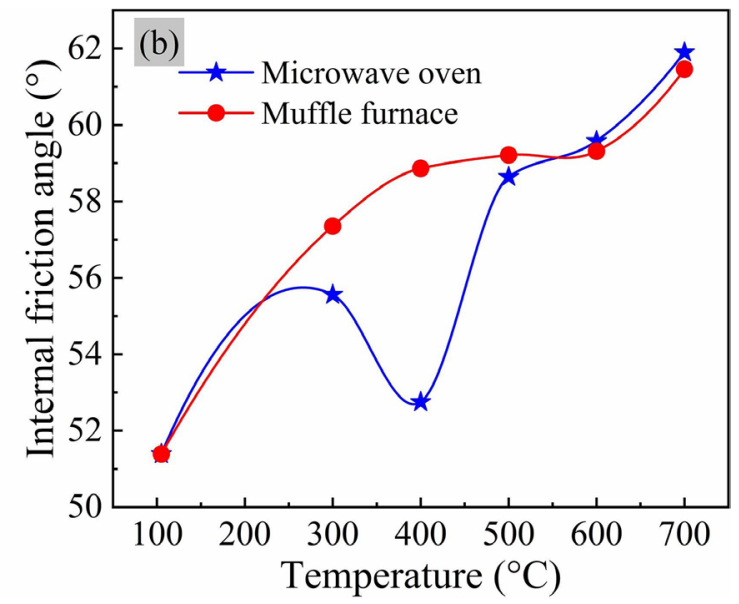

specimens, and it is harder than MMT particle, which will also lead to an increase in shear strength of the specimens. On the other hand, the significant degree of disorder state of MMT after dehydroxylation cannot be ignored. The appearance of more active sites will lead to the local combination of the internal structure of the specimens ${ }^{34}$, thereby enhancing the shear strength of the specimens. But in the end, due to the influence of hot spots, the microwave heat-treated specimens cracked seriously at $700{ }^{\circ} \mathrm{C}$, the crack re-control the shear resistance, and the cohesion dropped again.

For the internal friction angle of the MMT specimens after heat treatment, the internal friction angle of the specimens shows an upward trend from $105-700{ }^{\circ} \mathrm{C}$, except for the slight decrease of the microwave heat-treated sample at $400{ }^{\circ} \mathrm{C}$. Same as the cohesion, the internal friction angle of the specimens heat-treated in the microwave oven is lower than that of the muffle furnace at $300-500{ }^{\circ} \mathrm{C}$. The internal friction angle of the microwave heat-treated specimens does not exceed the internal friction angle of the muffle furnace heat-treated specimens until $600{ }^{\circ} \mathrm{C}$. In fact, the internal friction angle of the MMT specimens after heat treatment is comprehensively controlled by particle size, cracks, and phase composition. The increment of internal friction angle at low temperature (before the large sale of dehydroxylation, no phase change has been formed) is because MMT loses the adsorbed water and interlayer water to dense the particles, the MMT particles that are initially smaller than $80 \mu \mathrm{m}$ are clustered together to form larger MMT particles, which will increase the friction between the particles. This effect is sufficient to offset the cracks caused by the shrinkage of the specimens, so the internal friction angle of the specimens increased. Microwave heat-treated specimens begin to dehydroxylate earlier and form denser crystals due to the 
interlayer structure collapsing, at the same time, the numerous active sites generated by dehydroxylation of MMT can not be ignored, which theoretically makes the internal friction angle rise faster. However, due to the existence of hot spots inside the MMT specimens heat-treated by microwave, more cracks were generated, especially at $700{ }^{\circ} \mathrm{C}$, the difference in cracks was more prominent. Under the similar area of the shear surface (circular section of the specimen), the effective shear area of the specimens is reduced, and there are fewer supporting points for resisting the shear force. Therefore, the internal friction angle of the microwave heat-treated specimens and the muffle furnace heat-treated specimens is close.

\subsection{Water stability}

Water is proved to dominate the stability failure of the slope existing muddy intercalation. According to the study of Sun et al. ${ }^{35}$, the cohesion and internal friction angle of muddy intercalation decrease about $60 \%$ and $39 \%$ from the natural to saturation state. Thus, evaluating the water resistance is necessary to muddy intercalation reinforcement.

Figure 11 exhibits the water immersion results of MMT after heat-treated by the microwave oven and muffle furnace.
First, we observed the water stability of the microwave heattreated specimens. The specimen heat-treated by microwave at $300{ }^{\circ} \mathrm{C}$ fails to keep integrity even less than five seconds. The $24 \mathrm{~h}$ soaking destroyed the $300^{\circ} \mathrm{C}$ heat-treated specimens, where the specimen completely disintegrated into particles with a diameter of 2-3 mm. Although the specimen of $400{ }^{\circ} \mathrm{C}$ still disintegrates after slight shaking, the structure can be considered relative integrity. The specimens heated over $500{ }^{\circ} \mathrm{C}$ significantly promote MMT resistance to the water, where no secondary cracks and fragments are observed.

For comparison, we also conducted a water immersion test on the muffle furnace heat-treated specimens. We can easily find that the $300{ }^{\circ} \mathrm{C}$ heat-treated specimens began to disintegrate after being immersed in water for 5 seconds. The difference between the microwave heat-treated specimen is that the muffle furnace heat-treated specimen was directly disintegrated into particles of a small size. After $24 \mathrm{~h}$ of water immersion, it disintegrated completely. The $400{ }^{\circ} \mathrm{C}$ heat-treated specimens disintegrated into particles with a diameter of 4-5 mm, larger than the particle size after the microwave heat-treated specimen disintegrated at $300{ }^{\circ} \mathrm{C}$. The specimen heat-treated by microwave at $500{ }^{\circ} \mathrm{C}$ was still damaged under slight disturbance after $24 \mathrm{~h}$ of water

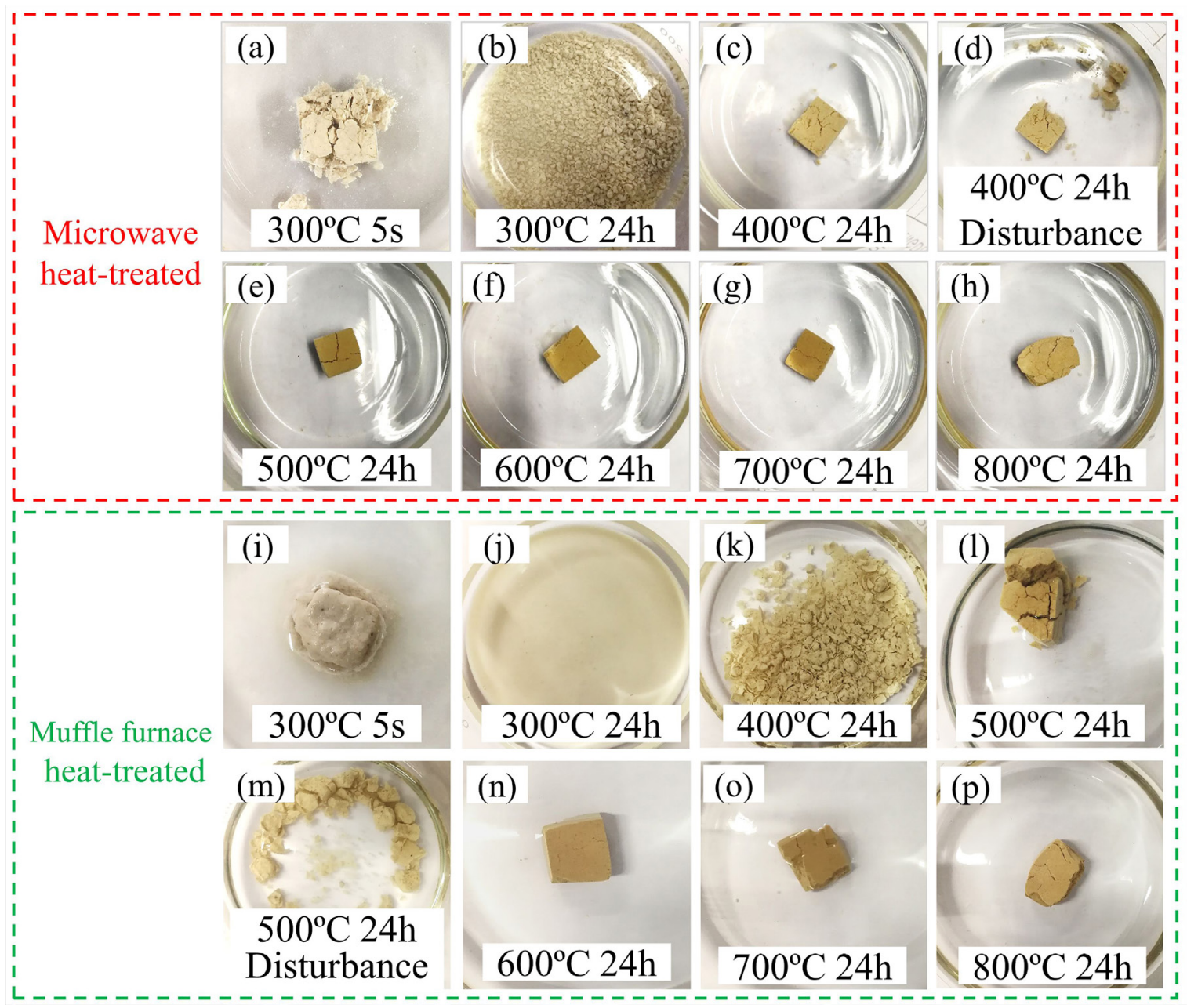

Figure 11. Water stability of MMT after heat treatment. 
immersion, which is also different from the microwave heattreated specimen. The specimens heat-treated at $600-800^{\circ} \mathrm{C}$ showed good water resistance.

Figure 12 demonstrates the mineralogical composition of heat-treated specimens before and after 20 days of the water immersion test. For the specimens after microwave heat treatment (marked with MW), We can easily find that after 20 days of immersion in water, the specimens treated at $300{ }^{\circ} \mathrm{C}$ and 400 showed significant changes in the diffraction peak position of MMT. Moreover, the MMT crystal interlayer space is almost the same as the received MMT specimen. However, the specimens' diffraction patterns heat-treated at $500{ }^{\circ} \mathrm{C}$ and above barely change before and after water immersion, which means that the MMT specimens treated at $500{ }^{\circ} \mathrm{C}$ are no longer affected by water. We inferred that the microwave heat treatment at $500^{\circ} \mathrm{C}$ can completely remove the interlayer water, thereby improving the water-resistance of the MMT specimen. However, according to the XRPD results of the muffle furnace heat-treated specimens (marked with MF), the specimen heat-treated at $500{ }^{\circ} \mathrm{C}$ in muffle furnace is still affected by water, the MMT absorbed water again, and the interlayer space increased significantly, this means that the $500{ }^{\circ} \mathrm{C}$ heat-treatment in the muffle furnace could not remove the interlayer water among the MMT crystal interlayer area. This phenomenon also reflects the advantages of microwave heat treatment compared to muffle furnace heating.

Combining the results of Figure 11 and Figure 12, it is found that the water-resistance of the microwave heat-treated specimens is better, so it is necessary to determine the optimal temperature of the microwave heat-treated MMT specimens in terms of water resistance. After microwave heat treatment at $300,400^{\circ} \mathrm{C}$, the specimen is seriously affected by water after water immersion, whether it is macroscopic disintegration or expansion of the crystal layer spacing in the XRPD pattern, so $300,400^{\circ} \mathrm{C}$ can not effectively enhance the water-resistance of montmorillonite. When the temperature reaches $500^{\circ} \mathrm{C}$, since the interlayer water is completely removed, and the thermogravimetric analysis and mass loss of the specimens

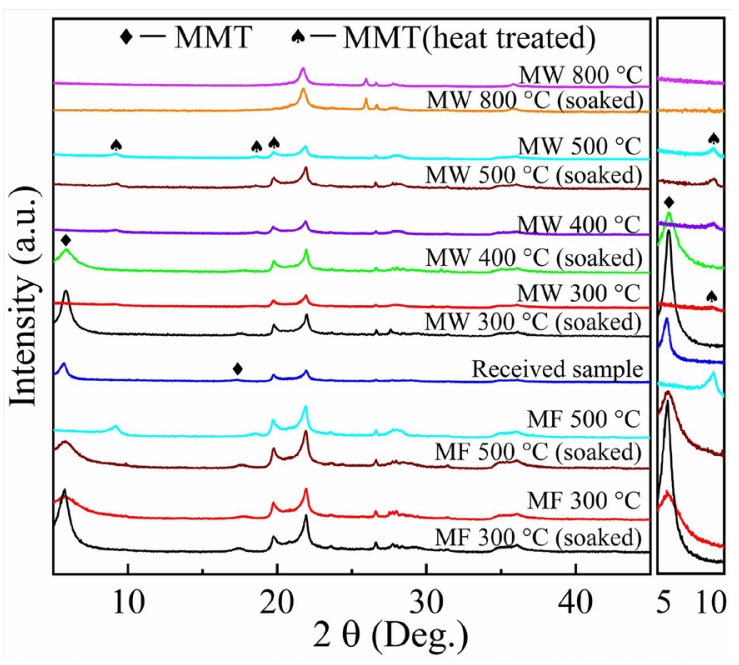

Figure 12. Specimens mineralogical composition before and after the water immersion test. after microwave heat treatment (Figure 8) indicated that montmorillonite has begun to dehydroxylate on a large scale at $500^{\circ} \mathrm{C}$, the interlayer structure of montmorillonite is no longer affected by water. Therefore, $500^{\circ} \mathrm{C}$ may be the optimal temperature for enhancing the water-resistance of montmorillonite.

\section{Conclusions}

This study investigates the mechanism of shear strength and water stability enhancement of montmorillonite heated by the microwave oven and muffle furnace from room temperature to $800{ }^{\circ} \mathrm{C}$ by evaluating the mineralogical composition, micromorphology, shear behavior, and water stability. We verified the existence of hot spots inside the microwave heattreated specimens by comparing the XRPD results of the internal and external samples. But the temperature monitoring has been carried out exclusively on the superficial portion of the specimens and, therefore, the exact behavior inside the specimens is unknown. In addition, the influence of the cracks produced by microwave heat treatment has not been evaluated under other types of mechanical stresses. What's more, this study lacks considering the interaction of multiple minerals in muddy intercalation exposed to microwaves. These should be improved in future research to promote microwave heating in reinforcing the muddy intercalation. The primary conclusions can be summarized as follows:

(1) The mineralogical evolution of microwave heat-treated montmorillonite can be divided into $105-300^{\circ} \mathrm{C}$, 300-600 ${ }^{\circ} \mathrm{C}, 600-800{ }^{\circ} \mathrm{C}$, corresponding to lose absorbed water and interlayer water, small scale of dehydroxylation at an uncertain temperature between 300-600 ${ }^{\circ} \mathrm{C}$ and large scale of dehydroxylation.

(2) Microwave heat treatment of montmorillonite is more efficient than that of muffle furnace, manifested as dehydroxylation at a lower temperature. In addition, there are hot spots inside the montmorillonite heattreated specimens, and this is closely related to the massive cracking of montmorillonite at $700^{\circ} \mathrm{C}$ and the loss of integrity at $800{ }^{\circ} \mathrm{C}$.

(3) The microwave significantly promotes the shear resistance of montmorillonite, where the maximum increases are $39.94 \%$ of cohesion at $600{ }^{\circ} \mathrm{C}$ and $20.54 \%$ of internal friction angle at $700{ }^{\circ} \mathrm{C}$. This enhancement is due to the rough surface and large particles produced by dehydroxylation and $\mathrm{Mg}$ Al spinel synthesis, and the significant degree of disorder state of MMT after dehydroxylation also plays a vital role.

(4) The microwave-heated montmorillonite over $500^{\circ} \mathrm{C}$ presents good integrity in the water immersion test over $24 \mathrm{~h}$ by completely removing the interlayer water of montmorillonite. Since water dominates the stability failure of slopes containing muddy intercalation, the most reasonable heating interval is $500-600^{\circ} \mathrm{C}$, considering the shear behavior and water stability. This is of great significance for promoting the practical application of microwave reinforcement of muddy intercalation slopes. 


\section{Acknowledgements}

This research was supported by the National Natural Science Foundation of China (52078442), Sichuan Science and Technology Program (2019JDJQ0037, 2020JDRC0091, 2021YFSY0006).

\section{References}

1. Haruo S. Process of slip-surface development and formation of slip-surface clay in landslides in Tertiary volcanic rocks, Japan. Eng Geol. 2001;61(4):199-220.

2. Liu J, Xu Q, Wang S, Subramanian SS, Wang L, Qi X. Formation and chemo-mechanical characteristics of weak clay interlayers between alternative mudstone and sandstone sequence of gently inclined landslides in Nanjiang, SW China. Environ Earth Sci. 2020;79:4701-15.

3. Chai B, Yin K, Du J, Xiao L. Correlation between incompetent beds and slope deformation at Badong town in the Three Gorges reservoir, China. Environ Earth Sci. 2013;69(1):209-23.

4. Yang YC, Xing HG, Yang XG, Chen M. Experimental study on the dynamic response and stability of bedding rock slopes with weak interlayers under heavy rainfall. Environ Earth Sci. 2018;77:12:433.

5. Skempton AW. Long-term stability of clay slopes. Geotechnique. 1964;14(2):77-102.

6. Ali Y. The effects of clay on landslides: a case study. Appl Clay Sci. 2007;37:77-85.

7. Regmi AD, Yoshida K, Cui P, Hatano N. Development of Taprang landslide, West Nepal. Landslides. 2016;14:1-18.

8. Zhang S, Xu Q, Hu Z. Effects of rainwater softening on red mudstone of deep-seated landslide, Southwest China. Eng Geol. 2016;204:1-13.

9. Ohlmacher GC. The relationship between geology and landslide Hazards of Atchison, Kansas, and Vicinity. Curr Res Earth Sci, 2001;244(1):1-16.

10. Li G, Jiang Z, Feng X, Zhang N, Xu X. Relation between molecular structure of smectite and liquefaction of mudstone. RSC Advances. 2015;5(30):23481-8.

11. Bergaya F, Lagaly G. Developments in clay science. USA: Elsevier; 2006. Chapter 1, General Introduction: Clays, Clay Minerals, and Clay Science; p. 1-18.

12. Ferrage E, Lanson B, Sakharov BA, Drits VA. Investigation of smectite hydration properties by modeling experimental X-ray diffraction patterns. Part I. Montmorillonite hydration properties. Am Mineral. 2005;90(8-9):1358-74.

13. Ferrage E, Kirk CA, Cressey G, Cuadros J. Dehydration of Camontmorillonite at the crystal scale. Part I: structure evolution. Am Mineral. 2007;92(7):994-1006.

14. Greeshma G, Zhang F, Andrew JA. Towards understanding the microstructural and structural changes in natural hierarchical materials for energy recovery: in-operando multi-scale X-ray scattering characterization of $\mathrm{Na}$ - and Ca-montmorillonite on heating to 1150 degrees C. Fuel. 2017;196:195-209.

15. Attar LA, Safia B, Ghani BA. Uptake of $137 \mathrm{Cs}$ and $85 \mathrm{Sr}$ onto thermally treated forms of bentonite. J Environ Radioact. 2018;193-194:36-43.

16. Wu P, Wu H, Li R. The microstructural study of thermal treatment montmorillonite from Heping, China. Spectrochim Acta A Mol Biomol Spectrosc. 2005;61(13-14):3020-5.
17. Bayram H, Önal M, Yılmaz H, Sarıkaya Y. Thermal analysis of a white calcium bentonite. J Therm Anal Calorim. 2010;101(3):873-9.

18. Emmerich K, Steudel A, Merz D. Dehydroxylation of dioctahedral smectites in water vapor atmosphere. Appl Clay Sci. 2017;137:1-5.

19. Chen Q, Zhu R, Ma L, Zhou Q, Zhu J, He H. Influence of interlayer species on the thermal characteristics of montmorillonite. Appl Clay Sci. 2017;135:129-35.

20. Zhang Y, Liu Q, Wu Z, Zhang Y. Thermal behavior analysis of two bentonite samples selected from China. J Therm Anal Calorim. 2015;121(3):1-9.

21. Arpia AA, Chen WH, Lam SS, Rousset P, de Luna MDG. Sustainable biofuel and bioenergy production from biomass waste residues using microwave-assisted heating: a comprehensive review. Chem Eng J. 2021;403:126233.

22. Perez-Martinez BT, Aboudzadeh MA, Schubert US, Leiza JR, Tomovska R. Microwave irradiation versus conventional heating assisted free-radical copolymerization in solution. Chem Eng J. 2020;399:125761.

23. Korichi S, Elias A, Mefti A, Bensmaili A. The effect of microwave irradiation and conventional acid activation on the textural properties of smectite: comparative study. Appl Clay Sci. 2012;59-60:76-83.

24. Franco F, Pozo M, Antonio Cecilia J, et al. Effectiveness of microwave assisted acid treatment on dioctahedral and trioctahedral smectites. The influence of octahedral composition. Appl Clay Sci. 2016;120:70-80.

25. Pardo L, Cecilia J, López-Moreno C, Hernández V, Pozo M, Bentabol M, et al. Influence of the structure and experimental surfaces modifications of 2:1 clay minerals on the adsorption properties of methylene blue. Minerals (Basel). 2018;8(8):359.

26. Santana LNL, Gomes J, Menezes RR, Neves GA, Lira HL, Segadães AM. Microstructure development in clays upon heat treatment: kinetics and equilibrium. Appl Clay Sci. 2017; 135:325-32.

27. Hu Q, Gu Y, Zeng J, He L, Tang H, Wei G, et al. Microwave irradiation reinforcement of weak muddy intercalation in slope. Appl Clay Sci. 2019;183:105324.

28. Osipov VI. Nanofilms of adsorbed water in clay: mechanism of formation and properties. Water Resour. 2012;39(7):709-21.

29. Hong W, Meng J, Li C, Yan S, He X, Fu G. Effects of temperature on structural properties of hydrated montmorillonite: experimental study and molecular dynamics simulation. Adv Civ Eng. 2020

30. Schreyer W, Schairer JF. Compositions and structural states of anhydrous mg-cordierites: a re-investigation of the central part of the system MgO-A12O3-SiO2. J Petrol. 1961;2(3):324-406.

31. Wu J, Lu C, Xu X, Wang D, Sang Y, Zhang C. Influence of silica phase transformation on synthesis of cordierite ceramic. J Aust Ceram Soc. 2017;53(2):499-510.

32. Whittaker AG. Diffusion in microwave-heated ceramics. Chem Mater. 2005;17(13):3426-32.

33. Li D, Lu M, Cai Y, Cao Y, Zhan Y, Jiang L. Synthesis of high surface area $\mathrm{MgAl} 2 \mathrm{O} 4$ spinel as catalyst support via layered double hydroxides-containing precursor. Appl Clay Sci. 2016;132-133:243-50.

34. Garg N, Skibsted J. Thermal activation of a pure montmorillonite clay and its reactivity in cementitious systems. J Phys Chem C. 2014;118(21):11464-77.

35. Sun H-Y, Pan P, Lü Q, Wei Z-L, Xie W, Zhan W. A case study of a rainfall-induced landslide involving weak interlayer and its treatment using the siphon drainage method. Bull Eng Geol Environ. 2019;78(6):4063-74. 